\title{
Phenyliodine(III) Bis(trifluoroacetate) as a Radical Cation Generating Reagent
}

\author{
Lennart Eberson, ${ }^{a \dagger}$ Michael P. Hartshorn ${ }^{\mathrm{b}}$ and Ola Persson ${ }^{\mathrm{a}}$ \\ ${ }^{a}$ Chemical Center, Lund University, PO Box 124, S-22100 Lund, Sweden and ${ }^{\mathrm{b}}$ Department of Chemistry, University of \\ Canterbury, Christchurch, New Zealand
}

\begin{abstract}
Eberson, L., Hartshorn, M. P. and Persson, O., 1995. Phenyliodine(III) Bis(trifluoroacetate) as a Radical Cation Generating Reagent. - Acta Chem. Scand. 49: 640-644 (C) Acta Chemica Scandinavica 1995.

The use of phenyliodine(III) bis(trifluoroacetate) (PIFA) as a one-electron oxidant for aromatic compounds has been explored. In trifluoroacetic acid or 1,1,1,3,3,3hexafluoro-2-propanol, a number of radical cations were generated in the temperature range -10 to $20^{\circ} \mathrm{C}$ and structurally assigned by EPR spectroscopy. The oxidative power of PIFA was found to be similar to that of thallium(III) trifluoroacetate under the conditions employed. Thus PIFA oxidation is a useful, less toxic complement to existing methods of radical cation generation. 1.1.1.3.3.3Hexafluoro-2-propanol was found to be an excellent solvent for radical cations.

The use of PIFA in 'inverted spin trapping' with $\alpha$-phenyl- $N$-tert-butylnitrone (PBN) was investigated briefly, and it was found that it sustains this reaction with nucleophiles such as fluoride, chloride and acetate ion, tetramethylsuccinimide anion and benzotriazolate anion.
\end{abstract}

It was shown recently ${ }^{1}$ that 4 -substituted phenol ethers could be substituted oxidatively by various nucleophiles, using phenyliodine(III) bis(trifluoroacetate) (PIFA) as the oxidant. In several cases the intermediacy of radical cations was inferred from their EPR spectral detection in solutions containing only substrate and PIFA.

One such case was 4-tert-butylanisole (1), which upon treatment with PIFA in hexafluoroisopropyl alcohol (1,1,1,3,3,3-hexafluoro-2-propanol) at room temperature generated a stable EPR spectrum, assigned to $\mathbf{1}^{{ }^{+}}$and decaying over a period of $\approx 1 \mathrm{~h}$. The formation and stability of this radical cation suggested that PIFA in hexafluoroisopropyl alcohol or another suitable solvent might provide an alternative radical cation generating reagent, useful as a substitute and/or complement to other methods, e.g. oxidation by $\mathrm{Tl}^{\mathrm{III}}$ trifluoroacetate, ${ }^{2} \mathrm{Hg}^{\mathrm{II}}$ trifluoroacetate-UV light, ${ }^{3}$ 2,3-dichloro-4,5-dicyanobenzoquinone-trifluoroacetic $\mathrm{acid}^{4}$ or tetranitromethane-trifluoroacetic acid-light. ${ }^{5}$ In what follows, the use and scope of PIFA for the generation of radical cations is described.

\section{Results}

4-tert-Butylanisole (1). Repetition of the experiment by Kita et al. ${ }^{1}$ under somewhat different concentration conditions gave the spectrum of Fig. 1a, identical to the pub-

\rceil$_{\text {To whom }}$ correspondence should be addressed.

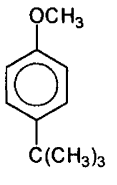

1<smiles>COc1ccc(C(C)(C)C)cc1-c1cc(C(C)(C)C)ccc1OC</smiles>

2<smiles>Cc1c(C)c(C)c(C)c(C)c1C</smiles>

3 lished one apart from the difference caused by the difference in modulation amplitude ( 0.05 vs. $0.005 \mathrm{mT})$. The persistency of the corresponding radical was rather high, as reported (see insert to Fig. 1a). The best fit to a doubleexponential function was obtained with $k_{\mathrm{up}}=0.28(2)$ $\min ^{-1}$ and $k_{\text {down }}=0.12(1) \mathrm{min}^{-1}$. Such persistency is unexpected for an anisole-type radical cation, in the light of the high reactivity of 1-methoxynaphthalene radical cation in dimerization even at much lower temperatures. ${ }^{6}$ In fact the only radical cation with could be detected in the latter system by EPR spectroscopy using a range of generation techniques was that of the dehydrodimer, 4,4' dimethoxy-1,1'-binaphthalene. Even if the tert-butyl group might be expected to exert some hindrance for further reactions of $\mathbf{1}^{+}$, it can hardly block the most reactive 2-position completely. Exploration of other possible candidates for a stable EPR spectrum led us to examine the possibility of dehydrodimer formation. ${ }^{7}$

Cyclic voltammetry of 1 in dichloromethane- $\mathrm{Bu}_{4} \mathrm{NPF}_{6}$ $\left(0.2 \mathrm{~mol} \mathrm{dm}^{-3}\right)$ showed an oxidation peak at $E_{\mathrm{pa}}=1.67 \mathrm{~V}$ $(\mathrm{Ag} / \mathrm{AgCl})$, with no corresponding cathodic peak seen up to a sweep rate of $50 \mathrm{~V} \mathrm{~s}^{-1}$. However, a small cathodic 
peak at $1.48 \mathrm{~V}$ indicated that a different species had been formed in the anodic sweep. Repeated cycling caused this peak to grow and also the development of a matching anodic peak at about $1.55 \mathrm{~V}$.

The dehydrodimer of 1 (2,2' -dimethoxy-5,5' -di-tertbutylbiphenyl, 2) was prepared in ca. $10 \%$ yield by $\mathrm{Tl}^{\mathrm{III}}$ trifluoroacetate oxidation ${ }^{8}$ of 1 . Cyclic voltammetry of 2 showed a reversible couple with $E_{\mathrm{pa}}$ and $E_{\mathrm{pc}}$ at 1.50 and $1.44 \mathrm{~V}$, respectively, at $0.1 \mathrm{~V} \mathrm{~s}^{-1}$. These values matched those of the secondary couple formed upon repeated cycling of the cyclic voltammogram of $\mathbf{1}$. Treatment of $\mathbf{2}$ with PIFA in hexafluoroisopropyl alcohol generated the EPR spectrum of Fig. 1b, identical with that obtained from 1 . It decayed with a rate constant of $0.11(1) \mathrm{min}^{-1}$, in agreement with the rate constant $k_{\text {down }}$ above. The spectrum was simulated by the following parameters: $a^{\mathrm{OCH}_{3}} 0.227(6 \mathrm{H}), a^{\mathrm{H} 3} 0.25(2 \mathrm{H}), a^{\mathrm{H} 6} 0.046, a^{\mathrm{C}^{\left(\mathrm{CH}_{3}\right)_{3}}}$ $0.023 \mathrm{mT}$. The same spectrum was generated by oxidation of $\mathbf{1}$ or $\mathbf{2}$ by DDQ-trifluoroacetic acid or $\mathrm{Tl}^{\mathrm{III}}$ trifluoroacetic acid at room temperature.

In order to generate $\mathbf{1}^{+}$for a comparison, the substrate was irradiated in dichloromethane together with

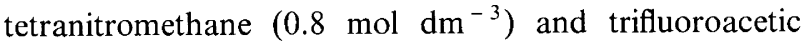
acid $\left(0.4 \mathrm{~mol} \mathrm{dm}^{-3}\right)$ at $-60^{\circ} \mathrm{C}$. Figure 2 shows the EPR
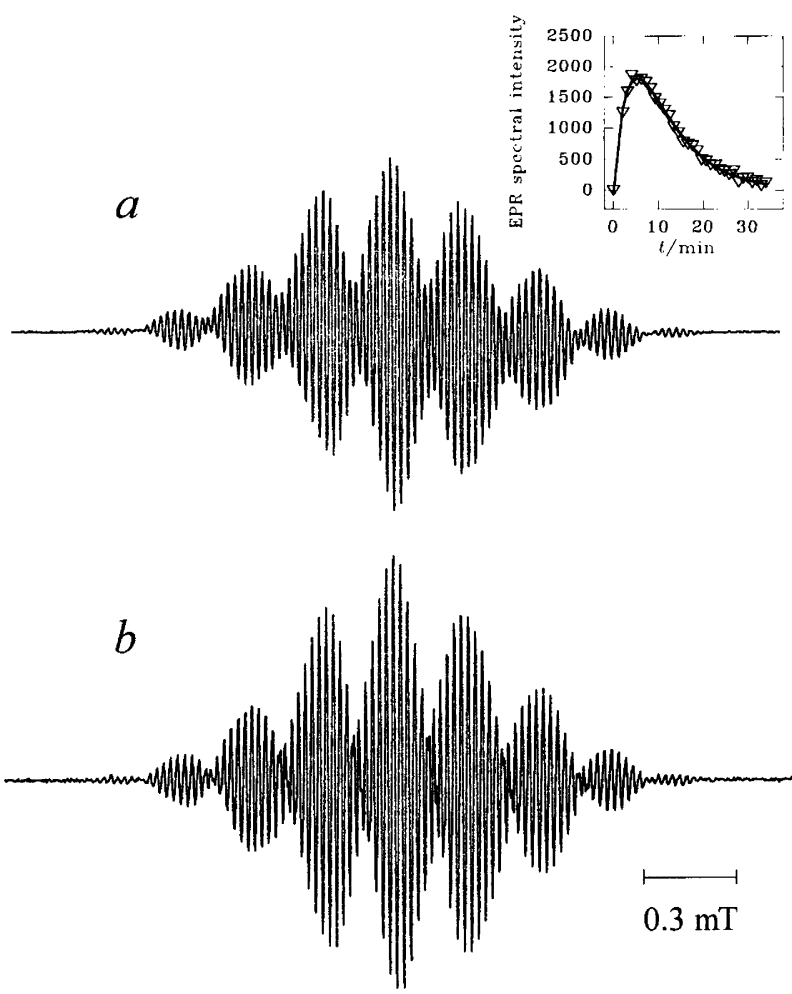

Fig. 1. (a) EPR spectrum from a solution of 4-tert-butylanisole $\left(14 \mathrm{mmol} \mathrm{dm}^{-3}\right.$ ) and PIFA (ca. $1.5 \mathrm{mmol} \mathrm{dm}^{-3}$ ) in hexafluoroisopropyl alcohol, recorded at $-10^{\circ} \mathrm{C}$. Insert: time dependency of the EPR signal (middle line) at $-10^{\circ} \mathrm{C}$. (b) EPR spectrum from a solution of 2,2'-dimethoxy-5, $5^{\prime}$ di-tert-butylbiphenyl $\left(3 \mathrm{mmol} \mathrm{dm}^{-3}\right)$ and PIFA $(8 \mathrm{mmol}$ $\mathrm{dm}^{-3}$ ) in hexafluoroisopropyl alcohol, recorded at $-10^{\circ} \mathrm{C}$.

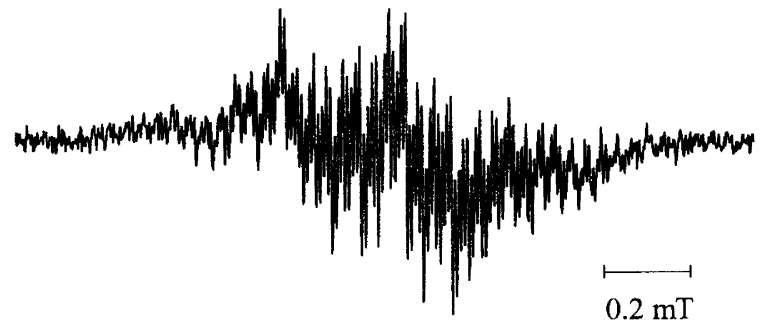

Fig. 2. EPR spectrum from a solution of 4-tert-butylanisole $\left(70 \mathrm{mmol} \mathrm{dm}{ }^{-3}\right)$, tetranitromethane $\left(0.8 \mathrm{~mol} \mathrm{dm}^{-3}\right)$ and trifluoroacetic acid $\left(0.8 \mathrm{~mol} \mathrm{dm}^{-3}\right)$, irradiated by light of $\lambda>430 \mathrm{~nm}$ at $-60^{\circ} \mathrm{C}$.

spectrum recorded under these conditions, distinctly different from that of $\mathbf{2}^{+}$(Fig. 1).

Other substrates. Exploratory studies soon showed that PIFA is an oxidant capable of oxidizing aromatic substrates $(\mathrm{ArH})$ with $E^{\circ}\left(\mathrm{ArH}^{\circ} / \mathrm{ArH}\right)<2.1 \mathrm{~V}(\mathrm{Ag} / \mathrm{AgCl})$, as shown in Table 1. Trifluoroacetic acid was employed as the solvent, since its freezing point is lower than that of hexafluoroisopropyl alcohol and thus allowed for the convenient recording of the EPR spectra of the less stable radical cations. However, to document the truly excellent properties of hexafluoroisopropyl alcohol, with $\mathrm{p} K=9.3$, as a solvent for radical cations, a few compounds were studied in this solvent at room temperature. One can, for example, note that the radical cation from $4,4^{\prime}$ dimethoxy-1,1'-binaphthalene is relatively stable in hexafluoroisopropyl alcohol at room temperature, decaying with a rate constant of ca. $0.06 \mathrm{~min}^{-1}$ (cf. ca. $0.07 \mathrm{~min}^{-1}$ in TFA). Other radical cations from 1,1' binaphthalenes, such as those from $3,3^{\prime}, 4,4^{\prime}-, 4,4^{\prime}, 6,6^{\prime}-$ and $2,2^{\prime}, 4,4^{\prime}$-tetramethylbinaphthalene, survived long enough in hexafluoroisopropyl alcohol at room temperature to make possible the recording of well resolved spectra, whereas the radical cation from $4,4^{\prime}, 5,5^{\prime}$-tetramethylbinaphthalene was too shortlived. In further studies of radical cation generation in hexafluoroisopropyl alcohol by other oxidants ${ }^{9}$ we have been able to extend the halflifes of these binaphthalene radical cations and others by a factor of more than 100 !

For radical cations known to be stable, the components were mixed at room temperature, whereas less stable cations were generated by mixing ca. $-10^{\circ} \mathrm{C}$. EPR spectra in TFA solutions were recorded at $-11^{\circ} \mathrm{C}$. Well resolved spectra of monomeric radical cations were usually obtained, but for cases where dehydrodimerization has been clearly established in other methods of generation, EPR spectra of dehydrodimer radical cations were seen also from PIFA oxidation (1-methoxynaphthalene, 1,2-dimethylnaphthalene).

However, in some cases the PIFA method failed, not because radical cations were not formed but because they were not stable enough under the conditions employed. Hexamethylbenzene (3) was a typical case of this behaviour. Even when the reactants were mixed outside the 
Table 1. Oxidation of aromatic substrates (ArH) by PIFA in trifluoroacetic acid. The EPR spectra were recorded at $-11^{\circ} \mathrm{C}$. Electrode potentials were obtained from Refs. 10a, 17, 26 and 27.

\begin{tabular}{|c|c|c|c|}
\hline $\mathrm{ArH}$ & $\begin{array}{l}E^{\circ}\left(\mathrm{ArH}^{-+} / \mathrm{ArH}\right) \text { or } \\
E_{\mathrm{pa}} / \mathrm{V} \text { vs. } \mathrm{Ag} / \mathrm{AgCl}\end{array}$ & $\begin{array}{l}\text { Spectrum recorded } \\
\text { of }\end{array}$ & $\begin{array}{l}\text { Ref. to EPR } \\
\text { spectrum }\end{array}$ \\
\hline 1,3,5-Tri-tert-butylbenzene & 2.05 & $\mathrm{ArH}^{+}$ & 27 \\
\hline Durene & 1.87 & $\begin{array}{l}\left(1,2,4,5,6,8-\text { Hexa- }^{-}\right. \\
\text {methylanthracene })^{\circ+}\end{array}$ & 11 \\
\hline Pentamethylbenzene & 1.79 & $\begin{array}{l}\left(1,2,3,4,5,6,7,8-\text { Octa- }^{-}\right. \\
\text {methylanthracene })^{\circ+}\end{array}$ & $10 a$ \\
\hline $4,4^{\prime}$-Bitoluene & 1.69 & 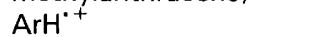 & 2 \\
\hline 4-tert-Butylanisole & 1.67 & $(\mathrm{Ar}-\mathrm{Ar})^{+}$ & \\
\hline $\begin{array}{l}\text { Hexamethylbenzene (mixed at }-10^{\circ} \mathrm{C} \text { in the cavity } \\
\text { of the EPR spectrometer) }\end{array}$ & 1.66 & $\mathrm{ArH}^{+}$ & 3 \\
\hline Hexaethylbenzene & 1.63 & $\mathrm{ArH}^{+}$ & 27 \\
\hline 1,2-Dimethylnaphthalene & 1.60 & $(\mathrm{Ar}-\mathrm{Ar})^{\cdot+}$ & 17 \\
\hline $2,2^{\prime}, 4,4^{\prime}-$ Tetramethyl- $1,1^{\prime}$-binaphthalene ${ }^{a}$ & 1.55 & $\mathrm{ArH}^{+}+$ & 17 \\
\hline Dibenzo-1,4-dioxin & 1.50 & $\mathrm{ArH}^{\cdot+}$ & 25 \\
\hline $2,2^{\prime}$-Dimethoxy-5,5' -di-tert-butylbiphenyl & 1.47 & $\mathrm{ArH}^{\cdot+}$ & \\
\hline 1-Methoxynaphthalene & 1.47 & $(\mathrm{Ar}-\mathrm{Ar})^{\cdot+}$ & 6 \\
\hline 1,3,5,7-Tetramethylnaphthalene & 1.45 & $\mathrm{ArH}^{+}$ & 26 \\
\hline $3,3^{\prime}, 4,4^{\prime}$-Tetramethyl-1, $1^{\prime}$-binaphthalene ${ }^{a}$ & 1.41 & $\mathrm{ArH}^{\circ}+$ & 17 \\
\hline Anthracene & 1.41 & $\left(9-\mathrm{CF}_{3} \mathrm{COOAr}^{\cdot+}\right.$ & 12 \\
\hline $4,4^{\prime}, 6,6^{\prime}$-Tetramethyl-1, $1^{\prime}$-binaphthalene ${ }^{a}$ & 1.40 & $\mathrm{ArH}^{+}{ }^{3}$ & 17 \\
\hline $4,4^{\prime}, 5,5^{\prime}$-Tetramethyl-1, $1^{\prime}$-binaphthalene ${ }^{b}$ & 1.38 & $\mathrm{ArH}^{\circ}+$ & 17 \\
\hline $1,4,5,8$-Tetramethylnaphthalene & 1.32 & $\mathrm{ArH}^{+}$ & 22 \\
\hline Pyrene & 1.20 & $\mathrm{ArH}^{\circ}+$ & 27 \\
\hline $4,4^{\prime}$-Dimethoxy-1, $1^{\prime}$-binaphthalene & 1.19 & $\mathrm{ArH}^{\circ+}$ & 6 \\
\hline $4,4^{\prime}-\operatorname{Bis}\left(d_{3}-\right.$ methoxy $)-1,1^{\prime}$-binaphthalene ${ }^{c}$ & 1.19 & $\mathrm{ArH}^{\cdot+}$ & 6 \\
\hline 9,10-Dimethylanthracene & 1.11 & $\mathrm{ArH}^{+}$ & 27 \\
\hline Perylene & 1.10 & $\mathrm{ArH}^{+}$ & 27 \\
\hline $1,2,3,4,5,6,7,8$-Octamethylanthracene & 0.86 & $\mathrm{ArH}^{+}+$ & $10 a$ \\
\hline Pentacene & 0.74 & $\mathrm{ArH}^{\circ}+$ & 27 \\
\hline
\end{tabular}

${ }^{a}$ This radical cation was also generated in hexafluoroisopropyl alcohol at room temperature, and persisted for 5-10 min under these conditions. ${ }^{b}$ Persisted for 2-3 min in hexafluoroisopropyl alcohol at room temperature. ${ }^{c}$ Reaction run in hexafluoroisopropyl alcohol at room temperature; $k_{\text {decay }}=0.06 \mathrm{~min}^{-1}$.

EPR cavity at ca. $-10^{\circ} \mathrm{C}$, the resulting solution was EPR-silent by the time the first spectrum could be recorded (about 2 min after mixing). The typical yellow colour signalling the presence of $\mathbf{3}^{+}$did appear immediately upon mixing but disappeared within $1 \mathrm{~min}$; the addition of $2 \%$ of a stronger acid (methanesulfonic acid) did not influence this process. However, by mixing the reagents (concentrations around $30 \mathrm{mmol} \mathrm{dm}^{-3}$ ) with the sample tube kept at $-11^{\circ} \mathrm{C}$ in the EPR cavity and recording by the automation routine, it was possible to record the transient spectrum of $3^{+}$and determine its decay rate constant to be 5-7 $\mathrm{min}^{-1}$. Under similar conditions the reaction between $\mathrm{Tl}^{\mathrm{III}}$ trifluoroacetate and $\mathbf{3}$ in TFA gave a spectrum of $3^{+}$appearing and disappearing with about the same rate constant, $k_{\text {up }}$ and $k_{\text {down }}$ being 0.42 and $0.37 \mathrm{~min}^{-1}$, respectively.

The facile formation of $1,2,3,4,5,6,7,8$-octamethylanthracene radical cation on oxidation of pentamethylbenzene in an acidic medium is a diagnostic reaction for initial formation of the transient pentamethylbenzene radical cation. ${ }^{10}$ This reaction worked well with PIFA, as did the analogous oxidation of durene with formation of 1,2,4,5,6,8-hexamethylanthracene radical action. ${ }^{11}$ Oxidation of anthracene produced the EPR spectrum of 9-trifluoroacetoxyanthracene. ${ }^{12}$
The radical cation of $4,4^{\prime}$-bitoluene was obtained by PIFA oxidation of this substrate, but not from toluene (which is possible with $\mathrm{Tl}^{\mathrm{III}}$ ). ${ }^{2}$

PIFA oxidations were not promoted by photolysis using UV or filtered light (cut-off at 345 or $430 \mathrm{~nm}$ ).

Reaction between PIFA and spin traps. The reaction between PIFA and $\alpha$-phenyl- $N$-tert-butylnitrone (PBN), performed in dichloromethane at room temperature, led to the formation of a strong signal (1:1:1 triplet of $a^{\mathrm{N}}=0.81 \mathrm{mT}$ ) of the corresponding carbonylaminoxyl radical, $\mathrm{PhCON}\left(\mathrm{O}^{\circ}\right) \mathrm{Bu}^{\mathrm{t}}$, often denoted $\mathrm{PBNOx}$ (lit. ${ }^{13}$ $\left.a^{\mathrm{N}}=0.80\right)$. This signal was the only one observed even when a large excess of PBN was employed. With 5,5dimethylpyrroline $\mathrm{N}$-oxide (DMPO) no signal of the acylnitroxyl radical was detected, whereas a weak signal (1:1:1 triplet with $\left.a^{\mathrm{N}}=0.65 \mathrm{mT}\right)$ was detected from 3,3,5,5-tetramethylpyrroline $N$-oxide (TMPO). ${ }^{14}$

When PBN was treated with PIFA in the presence of a nucleophile $\mathrm{Nu}^{-}$, the corresponding spin adducts $\mathrm{Nu}-$ $\mathrm{PBN}^{*}$ were formed, besides PBNOx. The following nucleophiles, in the form of their tetrabutylammonium salts, were tested: fluoride ion, which gave both the monofluoro adduct $\left(a^{\mathrm{N}}=1.27, \quad a^{\mathrm{H}}=0.11, \quad a^{\mathrm{F}}=4.55 \quad \mathrm{mT} ; \quad\right.$ lit. $^{15}$ $\left.a^{\mathrm{N}}=1.27, a^{\mathrm{H}}=0.11, a^{\mathrm{F}}=4.57 \mathrm{mT}\right)$ and the difluoro com- 
pound (the $\mathrm{CH}$ of the monofluoro adduct has been substituted by a fluorine; $a^{\mathrm{N}}=1.27, a^{\mathrm{F}}(2 \mathrm{~F})=2.08 \mathrm{mT}$; lit. $^{15}$ $\left.a^{\mathrm{N}}=1.28, a^{\mathrm{F}}(2 \mathrm{~F})=2.12 \mathrm{mT}\right)$, chloride ion $(\mathrm{Cl}$ adduct: $a^{\mathrm{N}}=1.27, a^{\mathrm{H}}=0.089, a^{35 \mathrm{Cl}}=0.61, a^{37 \mathrm{Cl}}=0.51 \mathrm{mT}$; lit. ${ }^{13}$ $\left.a^{\mathrm{N}}=1.27, a^{\mathrm{H}}=0.089, a^{35_{\mathrm{Cl}}}=0.62, a^{37 \mathrm{Cl}}=0.51 \mathrm{mT}\right)$, hydrogendiacetate ion $\left(\mathrm{CH}_{3} \mathrm{COO}\right.$ adduct: $a^{\mathrm{N}}=1.36$, $a^{\mathrm{H}}=0.16 \mathrm{mT}$; lit. $\left.{ }^{15} a^{\mathrm{N}}=1.36, a^{\mathrm{H}}=0.16 \mathrm{mT}\right)$, tetramethylsuccinimide anion ( $N$-tetramethylsuccinimido adduct: $a^{\mathrm{N}}=1.43, a^{\mathrm{H}}=0.51, a^{\mathrm{N}^{\prime}}=0.13 \mathrm{mT} ;$ lit. ${ }^{15} a^{\mathrm{N}}=1.43$, $\left.a^{\mathrm{H}}=0.51, a^{\mathrm{N}^{\prime}}=0.14 \mathrm{mT}\right)$ and benzotriazolate ion $\left(N^{1}\right.$ benzotriazolato adduct: $\quad a^{\mathrm{N}}=1.37, \quad a^{\mathbf{H}}=0.16$, $a^{\mathrm{N}^{\prime}}=0.35 \mathrm{mT}$; lit. ${ }^{16} a^{\mathrm{N}}=1.38, a^{\mathrm{H}}=0.16, a^{\mathrm{N}^{\prime}}=0.35 \mathrm{mT}$. With tetrabutylammonium trinitromethanide only PBNOx was formed.

\section{Discussion}

In order to establish the characteristics of PIFA as a radical cation generating reagent, we have utilized a number of systems with diagnostic properties pertaining to the chemical reactivity of their radical cations. One characteristic reactivity of radical cations is that of dimerization to form a dication which upon proton loss gives the dehydrodimer [eqns. (1) and (2)], which normally is oxi-

$$
\begin{aligned}
& \mathrm{ArH}^{{ }^{+}}+\mathrm{ArH}^{{ }^{+}} \longrightarrow \mathrm{Ar}(\mathrm{H})-\mathrm{Ar}(\mathrm{H})^{2+} \\
& \mathrm{Ar}(\mathrm{H})-\mathrm{Ar}(\mathrm{H})^{2+} \stackrel{-2 \mathrm{H}^{+}}{\longrightarrow} \mathrm{Ar}-\mathrm{Ar} \stackrel{\mathrm{ArH}^{++}}{\longrightarrow} \mathrm{Ar}-\mathrm{Ar}^{{ }^{+}}
\end{aligned}
$$

dized at lower potential than that of $\mathrm{ArH}$ and thus appears as the radical cation $\mathrm{Ar}-\mathrm{Ar}^{\bullet+}$. This reaction type is favoured for alkoxy- and amino-substituted aromatics, ${ }^{7}$ but also seen for methyl aromatics, such as methylbenzenes ${ }^{2}$ and methylnaphthalenes. ${ }^{17}$ Obviously, this type of behaviour is an intrinsic property of the radical cation and not dependent upon its mode of generation under otherwise similar conditions. Thus it is not surprising that the stable radical cation obtained by PIFA oxidation of 4-tert-butylanisole is that of the dehydrodimer, 2,2' dimethoxy-5,5'-di-tert-butyl-1,1' -binaphthalene. The 4-tert-butylanisole radical cation can be prepared only by low-temperature photolysis of the substrate in the presence of a good acceptor, tetranitromethane, indicating some blocking action from the bulky tert-butyl group toward dimerization. From 1-methoxy-naphthalene only the dehydrodimer is seen under all types of conditions tried. ${ }^{6}$

In general, the behaviour of PIFA in the generation of radical cations resembles that of $\mathrm{Tl}^{\mathrm{III}}$ trifluoroacetate. $\mathrm{Re}$ actions are spontaneous and lead to the same types of radical cations from one and the same substrate. 1,3,5Tri-tert-butylbenzene represents the upper $E^{\circ}$ limit for the reaction, perhaps artificially so because of the unusually high stability of its radical cation due to steric hindrance. Durene and pentamethylbenzene come next in order of potentials; their radical cations are not persistent enough to be detectable but instead undergo complex carbocation-mediated reactions to give polymethylated an- thracenes and their radical cations. ${ }^{10 a, 11}$ The oxidation of anthracene leads to the radical cation of the monotrifluoroacetoxy substitution product, known from $\mathrm{Tl}^{\mathrm{III}}$ oxidation. ${ }^{12}$ Dehydrodimerization takes place upon oxidation of 4-tert-butylanisole, 1-methoxynaphthalene ${ }^{6}$ and 1,2-dimethylnaphthalene. ${ }^{5}$ The remaining substrates gave monomeric radical cations.

The failure to observe the hexamethylbenzene radical cation $3^{+}$from the PIFA oxidation of $\mathbf{3}$ was ascribed to the rapid decay of this species under the prevailing conditions. Earlier estimates of the stability of $3^{\circ+}$ have been various, ranging from 'very shortlived' (electrochemical evidence) ${ }^{18}$ to observable (half-life of the order of $10 \mathrm{~min}$; EPR, UV evidence) in neat TFA at $-10^{\circ} \mathrm{C},{ }^{10 a}$ or even at room temperature (EPR evidence). ${ }^{19}$ These contradictory results will be examined and resolved in a coming publication; ${ }^{20}$ here it suffices to say that $3^{\circ+}$ is unstable in neat TFA at $-11^{\circ} \mathrm{C}$; the decay rate constant of $3^{+}$ being ca. $6 \mathrm{~min}^{-1}$, following its generation by PIFA oxidation of 3 .

The properties of the radical cation of $\mathrm{PBN}, \mathrm{PBN}^{\cdot+}$, were studied in detail recently by direct observation (pulse radiolysis, laser flash photolysis) ${ }^{21}$ and were found to accord with the fact that spin adducts can be formed easily by oxidation of PBN-nucleophile mixtures by strong one-electron oxidants. ${ }^{14-16}$ This pathway, denoted 'inverted spin trapping', is initiated by oxidation of PBN to $\mathrm{PBN}^{\cdot+}$, followed by reaction of the latter by the nucleophile. Since PIFA was found to act as a one-electron reagent toward many $\mathrm{ArH}$, it would also be expected to sustain inverted spin trapping.

PIFA oxidizes PBN to PBNOx, as does the one-electron oxidant tris(4-bromophenyl)aminium ion in the presence of a weak nucleophile, the trifluoroacetate ion. ${ }^{15}$ With acetate ion added [in the form of tetrabutylammonium hydrogendiacetate, $\mathrm{Bu}_{4} \mathrm{~N}^{+} \mathrm{H}(\mathrm{OAc})_{2}{ }^{-}$], PIFA converted $\mathrm{PBN}$ also into $\mathrm{CH}_{3} \mathrm{COO}-\mathrm{PBN}^{\circ}$. With fluoride ion present, PIFA produced both $\mathrm{PhCHFN}\left(\mathrm{O}^{\circ}\right) \mathrm{Bu}^{t}$ and $\mathrm{PhCF}_{2} \mathrm{~N}\left(\mathrm{O}^{\circ}\right) \mathrm{Bu}^{\mathrm{t}}$, the latter being a product of further fluorination of $\mathrm{PhCHFN}\left(\mathrm{O}^{\circ}\right) \mathrm{Bu}^{\mathrm{t}}$. As before, ${ }^{15}$ this reaction is best explained as a radical-cation-mediated oxidative substitution [eqns. (3) and (4)] according to an ECE type mechanism.

$$
\begin{aligned}
& \mathrm{PhCHFN}\left(\mathrm{O}^{*}\right) \mathrm{Bu}^{t} \stackrel{-\mathrm{e}^{-}}{\longrightarrow} \mathrm{PhCHFN}\left(\mathrm{O}^{+}\right) \mathrm{Bu}^{t} \\
& \mathrm{PhCHFN}\left(\mathrm{O}^{+}\right) \mathrm{Bu}^{t} \underset{-\mathrm{e}^{-},+\mathrm{F}}{\stackrel{-\mathrm{H}^{+}}{\longrightarrow}} \mathrm{PhCF}_{2} \mathrm{~N}\left(\mathrm{O}^{-}\right) \mathrm{Bu}^{t}
\end{aligned}
$$

Other strong nucleophiles, such as the benzotriazolate ion, the tetramethylsuccinimide anion and the chloride ion, also gave spin adducts with PIFA and PBN, whereas a weaker nucleophile, the trinitromethanide ion, did not react in this fashion.

In conclusion, phenyliodine(III) bis(trifluoroacetate) is a versatile reagent for the generation of radical cations of low or intermediate reactivity. It also supports one-electron oxidation of the spin trap PBN, leading to spin ad- 
ducts via inverted spin trapping. It can replace thallium tris(trifluoroacetate) in most such applications, thus avoiding this highly toxic reagent.

\section{Experimental}

Materials. Substrates were synthesized by published procedures $\left(4,4^{\prime}\right.$-bitoluene), ${ }^{22}$ available from previous investigations (4-tert-butylanisole, ${ }^{23}$ tetramethyl-1,1' -binaphthalenes, ${ }^{17} 4,4^{\prime}$-dimethoxy-1,1'-binaphthalene and its $\mathrm{CD}_{3}$ analogue, ${ }^{6} 1,4,5,8-$ and 1,3,5,7-tetramethylnaphthalene $^{24}$ and $1,2,3,4,5,6,7,8$-octamethylanthracene) ${ }^{10 a}$ or purchased in highest possible commercial quality. PIFA and hexafluoroisopropyl alcohol were from Aldrich, and TFA was of UVASOL quality (Merck).

Preparation of 2,2' -dimethoxy-5,5'-di-tert-butylbiphenyl (2). Thallium(III) trifluoroacetate $(2.52 \mathrm{~g}, 4.63 \mathrm{mmol})$ was added to a solution of 4-tert-butylanisole $(1.52 \mathrm{~g}$, $9.25 \mathrm{mmol})$ in TFA $(12.5 \mathrm{ml})$. The reaction mixture was stirred at room temperature until a $\mathrm{Tl}^{\mathrm{III}}$ test was negative, and then poured into water and neutralized with sodium bicarbonate. Extraction with dichloromethane $(2 \times$ $20 \mathrm{ml}$ ), drying of the organic layer with magnesium sulfate and evaporation of the solvent gave a slightly yellow residue. Purification by column chromatography on silica using pentane-dichloromethane $(10: 1)$ as the eluent gave pure 2, yield $0.15 \mathrm{~g}(0.46 \mathrm{mmol}, 10 \%)$, m.p. $132-133^{\circ} \mathrm{C}$. ${ }^{1} \mathrm{H}$ NMR $\left(\mathrm{CDCl}_{3}\right): \delta 1.33(\mathrm{~s}, 18 \mathrm{H}), 3.77(\mathrm{~s}, 6 \mathrm{H}), 6.92$ (d, $2 \mathrm{H}, J=8.4 \mathrm{~Hz}), 7.31$ (d, $2 \mathrm{H}, J=2.6 \mathrm{~Hz}), 7.34$ (dd, $2 \mathrm{H}, 8.4, J=2.6 \mathrm{~Hz}$ ).

Generation of radical cations. A solution of the substrate (5-20 mmol $\left.\mathrm{dm}^{-3}\right)$ in TFA, contained in the EPR tube, was bubbled with argon for 2 min. PIFA was then added in solid form (final concentration ca. $20 \mathrm{mmol} \mathrm{dm}^{-3}$ ). The mixing was performed at room temperature for the less reactive systems, and at about $-10^{\circ} \mathrm{C}$ for the remaining ones. The generation of spin adducts was performed as described, ${ }^{14-16}$ using tetrabutylammonium salts of the appropriate nucleophiles.

EPR spectra were recorded on the Upgrade Version ESP 3220-200SH of the Bruker ER-200D spectrometer. Cyclic voltammetry was performed in dichloromethane $-\mathrm{Bu}_{4} \mathrm{NPF}_{6}\left(0.15 \mathrm{~mol} \mathrm{dm}{ }^{-3}\right)$, using the BAS-100 instrument.

Acknowledgements. Financial support (to L. E.) from the Swedish Natural Science Research Council and the Knut and Alice Wallenberg Foundation is gratefully acknowledged.

\section{References}

1. Kita, Y., Tohma, H., Hatanaka, K., Takada, T., Fujita, S., Mitoh, S., Sakurai, H. and Oka, S. J. Am. Chem. Soc. 116 (1994) 3684.

2. Elson, I. H. and Kochi, J. K. J. Am. Chem. Soc. 95 (1973) 5060 .

3. Lau, W. and Kochi, J. K. J. Org. Chem. 51 (1986) 1801.

4. Handoo, K. L. and Gadru, K. Curr. Sci. 55 (1986) 920.

5. Eberson, L., Hartshorn, M. P. and Svensson, J. O. J. Chem. Soc., Perkin Trans. 2 (1994) 1719.

6. Butts, C. P., Eberson, L., Hartshorn, M. P., Persson, O. and Robinson, W. T. Acta Chem. Scand. 49 (1995) 253.

7. Ronlan, A., Bechgaard, K. and Parker, V. D. Acta Chem. Scand. 27 (1973) 2375; Adams, R. N. Acc. Chem. Res. 2 (1966) 175.

8. McKillop, A., Turrell, A. G., Young, D. W. and Taylor, E. C. J. Am. Chem. Soc. 102 (1980) 6504.

9. Eberson, L., Hartshorn, M. P. and Persson, O. J. Chem. Soc., Chem. Commun. In press.

10. (a) Eberson, L. and Radner, F. Acta Chem. Scand. 46 (1992) 630. (b) J. Chem. Soc., Chem. Commun. (1991) 1233. (c) Sebastiano, Korp, J. D. and Kochi, J. K. J. Chem. Soc., Chem. Commun. (1991) 1481. For earlier observations of this phenomenon, see: (d) Fritz, H. P. and Artes, R. O. Electrochim. Acta 26 (1981) 417. (e) Lau, W. and Kochi, J. K. J. Am. Chem. Soc. 106 (1984) 7100.

11. Eberson, L., Radner, F. and Lindgren. M. Acta Chem. Scand. 47 (1993) 835.

12. Sullivan, P. D., Menger, E. M., Reddoch, A. H. and Paskovich, D. H. J. Phys. Chem. 82 (1978) 1158.

13. Buettner, G. R. Free Radical Biol. Med. 3 (1987) 259.

14. Eberson, L. J. Chem. Soc., Perkin Trans. 2 (1994) 171.

15. Eberson, L. J. Chem. Soc., Perkin Trans. 2 (1992) 1807.

16. Eberson, L. and Nilsson, M. Acta Chem. Scand. 47 (1993) 1129.

17. Eberson, L., Hartshorn, M. P. and Persson, O. J. Chem. Soc., Perkin Trans. 2 (1995) 409.

18. Parker, V. D. and Svanholm, U. Tetrahedron Lett. (1972) 471.

19. Kochi, J. K. Tetrahedron Lett. (1975) 41.

20. Eberson, L., Hartshorn, M. P., Persson, O. and Svensson, J. O. J. Chem. Soc., Perkin Trans. 2 (1995). In press.

21. Zubarev, V. and Brede, O. J. Chem. Soc., Perkin Trans. 2 (1994) 1821.

22. Ryabov, A. D., Deiko, S. A., Yatsimirsky, A. K. and Berezin, I. V. Tetrahedron Lett. 22 (1981) 3793.

23. Nyberg, K. and Wistrand, L.-G. J. Org. Chem. 43 (1978) 2613.

24. Eberson, L., Calvert, J. L., Hartshorn, M. P. and Robinson, W. T. Acta Chem. Scand. 47 (1993) 1025.

25. Yang, G. C. and Pohland, A. E. J. Phys. Chem. 76 (1972) 1504.

26. Bakker, M. G., Claridge, R. F. C. and Kirk, C. M. J. Chem. Soc., Perkin Trans 2 (1986) 1735.

27. Börnstein, L. Numerical Data and Fundamental Relationships in Science and Technology, Vol. 9d2, Springer-Verlag, Berlin 1980, pp. 6-20.

28. Howell, J. O., Goncalves, J. M., Amatore, C., Klasinc, L., Wightman, R. M. and Kochi, J. K. J. Am. Chem. Soc. 106 (1984) 3968.

29. Eberson, L. Electron Transfer Reactions in Organic Chemistry, Springer-Verlag, Heidelberg, 1987.

Received December 23, 1994. 